\title{
Development and Characterisation of Natamycin Mini-Matrices Prepared by Hot-Melt Extrusion for Vaginal Delivery
}

\author{
Betül Rumeysa Temel1,2, Işık Özgüney ${ }^{*}$ \\ ${ }^{1}$ Department of Pharmaceutical Technology, Faculty of Pharmacy, Ege University, Izmir, Turkey \\ ${ }^{2}$ Department of Pharmaceutical Technology, Faculty of Pharmacy, İzmir Katip Çelebi University, Izmir, Turkey \\ Email: *isik.ozguney@ege.edu.tr
}

How to cite this paper: Temel, B.R. and Özgüney, I. (2018) Development and Characterisation of Natamycin Mini-Matrices Prepared by Hot-Melt Extrusion for Vaginal Delivery. Journal of Materials Science and Chemical Engineering, 6, 47-54. https://doi.org/10.4236/msce.2018.63004

Received: December 8, 2017

Accepted: March 23, 2018

Published: March 26, 2018

Copyright $\odot 2018$ by authors and Scientific Research Publishing Inc. This work is licensed under the Creative Commons Attribution International License (CC BY 4.0).

http://creativecommons.org/licenses/by/4.0/

\begin{abstract}
In this study, bioadhesive mini-matrices of natamycin were prepared for vaginal application by hot-melt extrusion. In addition, melt viscosity measurements, thermogravimetric analysis, in vitro drug release studies and in vitro mucoadhesion test were performed. High molecular weight grades of $\mathrm{Klucel}^{\mathrm{TM}}$ hydroxypropylcellulose were used as a thermoplastic polymer. TEC and PEG 400 were chosen as plasticizer. According to the obtained results of melt viscosity measurements, the maximum torque of extrudates prepared using PEG 400 increased with increasing drug loading. The thermogravimetric analyses showed that natamycin is stable up to $198^{\circ} \mathrm{C}$ and this result gives the opportunity to hot melt extrussion process at $90^{\circ} \mathrm{C}$. In vitro drug release results showed that the release was extended up to 72 hours and drug release rate increased with increasing drug loading. In respect to the in vitro mucoadhesion test results, the values of work of mucoadhesion were found high as 771,977 $\mathrm{mN} \cdot \mathrm{mm}, 753,199 \mathrm{mN} \cdot \mathrm{mm}, 686,356 \mathrm{mN} \cdot \mathrm{mm}$ for the prepared hot melt extruded mini-matrices. Our results showed that the developed formulations were found worthy of further studies.
\end{abstract}

\section{Keywords}

Hot Melt Extrusion, Natamycin, Controlled Release, Bioadhesive, Vaginal Delivery

\section{Introduction}

Vaginal candidiasis (VC) often referred to as vulvovaginal candidiasis, is a common mucosal infection of vagina, mainly caused by Candida species. It is 
also known as second most prevalent mucosal infection later than bacterial vaginosis [1]. Yeast colonization occurs relatively frequently, with up to $30 \%$ of healthy asymptomatic women having a positive culture for yeast at any single point of time and up to $70 \%$ if followed longitudinally over a 1-year period [2]. Frequent recurrences of symptomatic vulvovaginitis result in considerable suffering and cost and have a markedly negative effect on sexual relations [3] [4].

Natamycin (NT), the first antifungal compound was approved by the US Food and Drug Administration for topical and ocular use [5]. Natamycin is a polyene antifungal produced by Streptomyces natalensis and related species. It has low toxicity and prevents the growth of mould and yeast [6]. NT has been applied topically as a suspension or ointment for skin, ocular or oral candidiasis, as an ointment for dermatomycosis. NT is poorly water-soluble drug and it causes bioavailability problems.

Controlled release of a poorly water soluble drug is one of the most challenging issues for the pharmaceutical scientist. In recent years, hot-melt extrusion technology has gained popularity due to pharmaceutical applications of poorly water-soluble drugs. The drug release is primarily controlled by the type and concentration of thermoplastic polymer, other excipients (e.g., plasticizers) and the processing conditions (e.g., temperature) [7]. In melt extrusion processes, the drug/carrier powder blend is exposed to elevated temperatures for approximately two to three minutes. Due to the simplicity of the manufacturing process, the properties of solid dispersions are not expected to change during scale-up, and when solid solutions are formed, the influence of the physical properties of the drug including the particle size distribution on drug release is eliminated [8]. With hot melt extrusion technique, the solubility can be increased also excipients and processing steps can be decreased.

The vagina is often an ideal route for drug administration because it allows for the administration of lower doses, steady drug levels, and less frequent administration than the oral route. With vaginal drug administration, absorption is unaffected by gastrointestinal disturbances, there is no first-pass effect, and use is discreet [9]. Also retantion time in the vagina can be optimized by using bioadhesive polymers.

Bioadhesion has received considerable attention in the medical literature due to the potential applications of drug delivery and wound care systems. The inclusion of mucoadhesive polymers into formulations has increased the residence time of the desired drug in the area, thereby boosting the efficacy of the treatment [10]. Apart from prolongation of drug release at the site of absorption, drug targeting to the affected site can also be realized [11] [12]. Fundamental thermodynamic quantities, such as surface free energies of both adhesive and substrate, determine the magnitude of the adhesive forces. However, this assembly and thus, effective bioadhesion is also a function of good wetting [13].

Hence an objective of the present study was to develop and produce vaginal mini matrices containing natamycin utilizing hot-melt extrusion technique to optimize drug delivery. Furthermore, the study objectives included characteriz- 
ing and evaluating this antifungal treatment modality using analytical, bioadhesion, dissolution, and thermal studies.

\section{Materials}

Natamycin (Shandong Freda Biotechnology Co., Ltd., Shandong, China), hydroxypropylcellulose (Klucel HF, Ashland Inc., Kentucky, USA), triethyl citrate (TEC, Aldrich Chemical Co., Inc., Milwaukee, Wis.) and polyethylenglycol 400 (PEG400, Merck, Darmstadt, Germany).

\section{Methods}

\subsection{Preparation of Hot Melt Extruded Matrices}

Based on previous studies, high molecular weight grades of Klucel ${ }^{\mathrm{TM}}$ hydroxypropylcellulose (HPC) were used as an thermoplastic polymer to develope the bioadhesive hot melt extruded formulations for vaginal delivery [13] [14]. TEC, PEG400 were chosen as plasticizer. Firstly, HPC and PEG400/TEC were mixed using a pestle and a mortar and then natamycin were added to this mixture (Table 1). The extrusion temperature is preferred as $90^{\circ} \mathrm{C}$ with a screw speed of $25 \mathrm{rpm}$. This raw material was fed into the hopper and transferred inside the heated barrel by rotating screws. The raw material was extruded with a co-rotating twin screw hot-melt extruder (Minilab HAAKE Rheomex CTW5, Thermo Fisher Scientific, Karlsruhe, Germany). The die diameter was preferred as $1.75 \mathrm{~mm}$. The torque values were determined.

\subsection{Melt Viscosity Measurements}

Melt viscosity values were measured by hot melt extruder automotically during the manufacturing process. The torque values were revealed depends on extrussion temperature and screw rotation speed. The following table consists of these values.

\subsection{Thermogravimetric Analysis of NT}

The thermal stabilities of natamycin was determined by the thermogravimetric analysis method (TGA) (Perkin Elmer TGA-4000). Sample weighed approximately $3 \mathrm{mg}$ were placed in a porcelain bowl and heated at a rate of $10^{\circ} \mathrm{C} / \mathrm{min}$ between $30^{\circ} \mathrm{C}-400^{\circ} \mathrm{C}$. The change in weight was determined.

Table 1. The compositions of formulations.

\begin{tabular}{cccccc}
\hline $\begin{array}{r}\text { The codes of } \\
\text { formulations }\end{array}$ & Natamycin (\%) & HPC (\%) & PEG400 (\%) & TEC (\%) & $\begin{array}{c}\text { Processing } \\
\text { Temperature }\left({ }^{\circ} \mathrm{C}\right)\end{array}$ \\
\hline F1 & 20 & 72 & - & 8 & 90 \\
F2 & 20 & 72 & 8 & - & 90 \\
F3 & 40 & 54 & 6 & - & 90 \\
F4 & 60 & 36 & 4 & - & 90 \\
\hline
\end{tabular}




\subsection{In Vitro Drug Release}

Extrudates of $5 \mathrm{~mm}$ length were used in drug release studies. The drug release was determined using $250 \mathrm{~mL}$ of $\mathrm{pH} 4.5$ citrate buffer containing $0.1 \%$ SDS; 70 $\mathrm{rpm} ; 37^{\circ} \mathrm{C}$ in a horizontal shaker incubator (Thermo Fisher Scientific Max $\mathrm{Q}^{\mathrm{mm}}$ 6000) according to the sink conditions. At predetermined time intervals, samples were collected and assayed by using UPLC (Accela, Thermo Fisher Scientific, Karlsruhe, Germany) at $304 \mathrm{~nm}$. The release medium was replaced with fresh medium every 24 hours.

\subsection{In Vitro Mucoadhesion Test}

The mucoadhesive strength of the formulations was evaluated by measuring the force required to detach the formulation from a $8 \%$ mucin solution using a $500 \mathrm{~g}$ load cell TPA in tension mode. The extrudates were attached to the lower end of the probe (P 10 Perspex, $\theta .10 \mathrm{~mm}$ ). The probe holding the extrudate was lowered on to the surface of the mucin with a constant speed of $0.1 \mathrm{~mm} \cdot \mathrm{s}^{-1}$ and a contact force of $0.005 \mathrm{~N}$ were applied. After keeping in contact surfaces for $180 \mathrm{~s}$, the probe was then moved vertically upward at a constant speed of $0.1 \mathrm{~mm} \cdot \mathrm{s}^{-1}$. Maximum detachment force (F) was obtained from the force-distance graph. The area under the curve (AUC) was calculated from force-distance plot as the mucoadhesion (M). The tests were conducted at $37^{\circ} \mathrm{C}$ and each experiment was carried out three times [15].

\section{Results and Discussion}

\subsection{Preparation of Extrudates}

The formulations and the processing conditions for the preparation of the vaginal bioadhesive mini matrices containing natamycin are listed in Table 1. HPC was chosen as the matrix-forming polymer since it is the only water-soluble cellulose derivative that is thermoplastic. HPC has a softening temperature in the range of $100^{\circ} \mathrm{C}-150^{\circ} \mathrm{C}$, depending on its molecular weight [16]. PEG400/TEC were used as plasticiser to facilitate the hot-melt extrusion process. Also, plasticisers provide die lubrication, reduce melt viscosity and improve melt uniformity [17]. Therefore, the extrudates could be produced at $90^{\circ} \mathrm{C}$ successfully.

In this study, four formulations have been tried but a colour change has been detected at F4 and it was concluded that drug loadings up to $40 \%$ could be extruded. So the characterization studies have been revealed with F1, F2, F3.

\subsection{Melt Viscosity Measurements}

Pharmaceutical polymers utilized in hot-melt extrusion typically require a plasticizer in order to reduce the $\mathrm{Tg}$ of the polymer and to facilitate the HME process [8]. According to the obtained results of melt viscosity measurements, the maximum torque values of F1 and F2 were close to each other and the mini matrices containing NT and HPC could be produced with low torque values us- 
ing both of the plasticisers. However the maximum torque of extrudates prepared using PEG400 increased with increasing drug loading (increased resistance to the flow of dispersed drug particles) [7] (Table 2).

\subsection{Thermogravimetric Analysis of NT}

The results obtained from the TGA studies showed that natamisin rapidly degraded from $198^{\circ} \mathrm{C}$ and weight loss increased (Figure 1).

\subsection{In Vitro Drug Release}

Comparing the release profiles of $\mathrm{F} 1$ and F2, the release profile of the extrudate containing PEG 400 is closer to the zero order release (Figure 2). F2 has 2 hours

Table 2. Maximum torque values obtained for different formulations and temperatures at screw speed of $25 \mathrm{rpm}$ during HME operation.

\begin{tabular}{cc}
\hline The codes of formulations & Maximum tork $(\mathrm{Nm})$ \\
\hline F1 & 0.38 \\
F2 & 0.33 \\
F3 & 0.56 \\
F4 & 0.75 \\
\hline
\end{tabular}

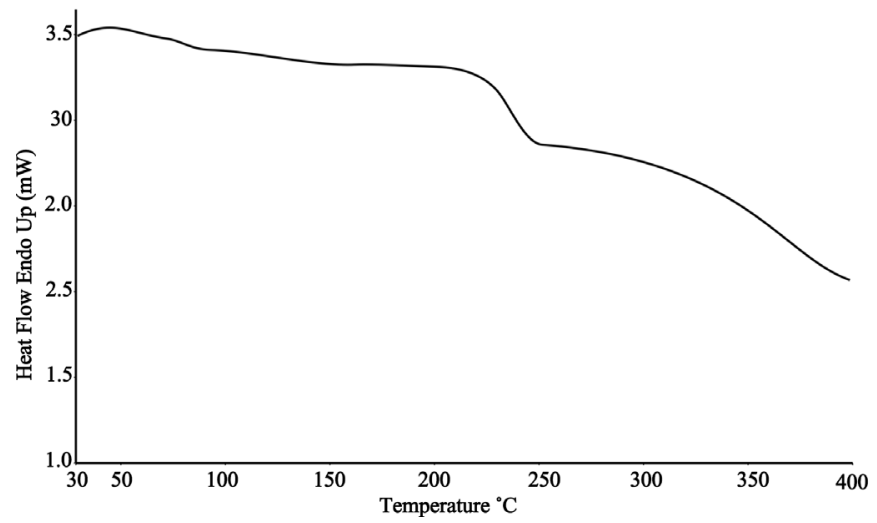

Figure 1. TGA curve of natamycin.

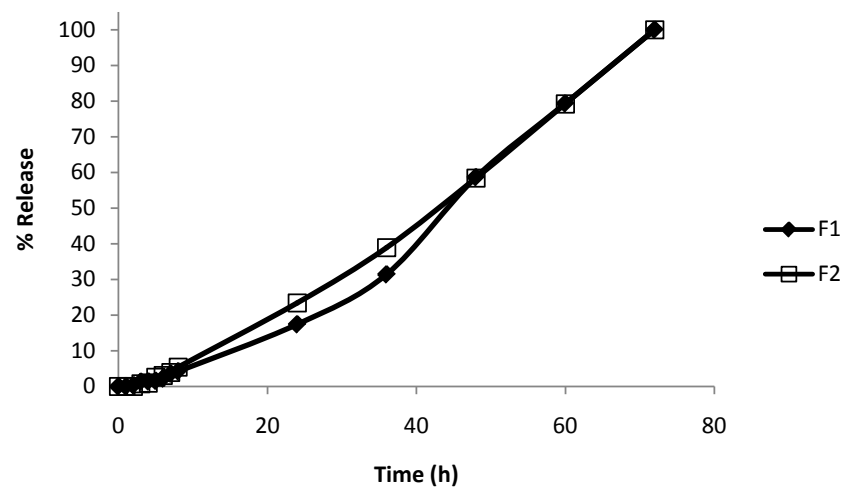

Figure 2. Effect of plasticiser type on the in vitro dug release profiles of HPC extrudates. 
lag time, and it released approximately 5\% and $23 \%$ of drug at the 8 . and 24 . hours respectively, whereas $\mathrm{F} 1$ reached $4 \%$ and $17 \%$ at the same time zones. Formulation $\mathrm{F} 1$ has just 1 hour lag time and its release is faster than formulation F2 for the first 4 hours. However, it was seen that the release rate of F2 is higher than formulation F1 up to 48 hour and than the release rates of two formulations were almost same.

Comparing the release profiles of F2 and F3, it was seen that drug release rate increased with increasing drug loading (Figure 3). The lag time is shortened on the extrudates containing 40\% NT. First 8 hours, F3 has faster release than F2. At the 24 hour, F2 has slightly more release rate than F3 and later two of formulations showed same release rates. According to the in vitro drug release results, the release was extended up to 72 hours.

\subsection{In Vitro Mucoadhesion Test}

The mucoadhesion results work of mucoadhesion and peak detachment force were calculated from the resulting force-distance plot obtained from the mucoadhesion test and given in Figure 4.

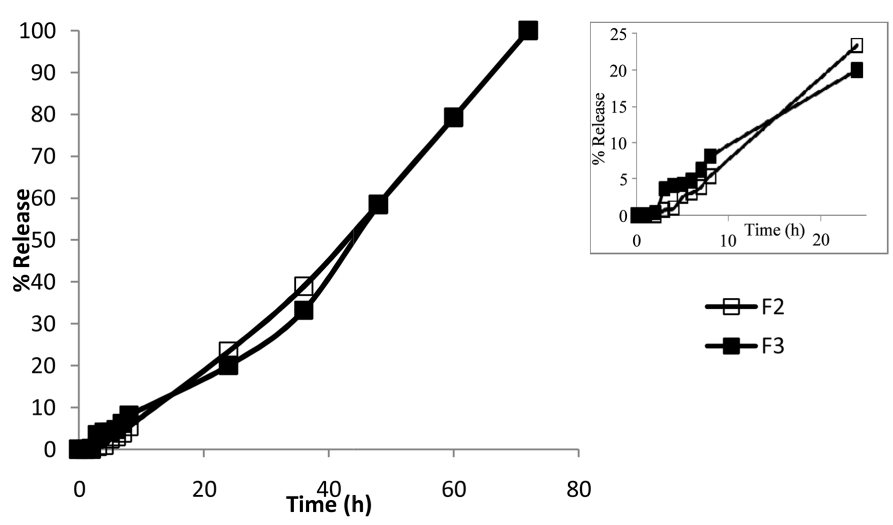

Figure 3. Effect of drug loading on the in vitro drug release profiles of HPC/PEG400 extrudates.

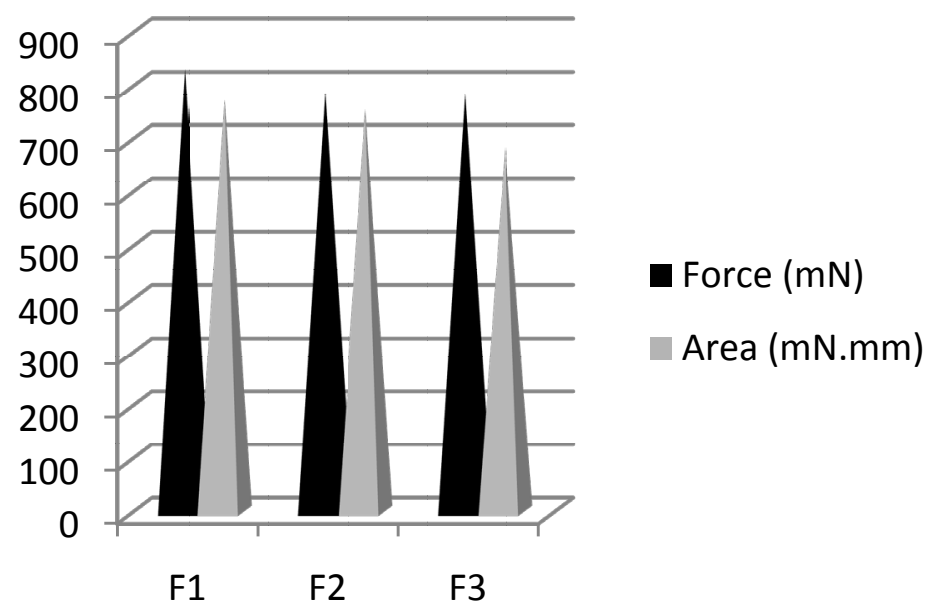

Figure 4. Results of mucoadhesion studies of the formulations with $8 \%$ mucin. 
The values of work of mucoadhesions were found as $771,977 \mathrm{mN} \cdot \mathrm{mm}$, $753,199 \mathrm{mN} \cdot \mathrm{mm}, 686,356 \mathrm{mN} \cdot \mathrm{mm}$ and peak detachment force values were found as $830,574 \mathrm{mN}, 786,693 \mathrm{mN}, 783,931 \mathrm{mN}$ for the $\mathrm{F} 1, \mathrm{~F} 2$, F3 respectively. These results showed that, the convenient mucoadhesion for the vaginal mucosa could be obtained by using hot melt extruded mini matrices produced with the matrix-forming bioadhesive polymer HPC. Additionally, it was observed that with increasing of natamycin ratio in the formulations, mucoadhesion was decreased.

\section{Conclusion}

This preliminary study demonstrated that NT loaded mini matrices for vaginal delivery can be produced by HME successfully and this could be a promising alternative formulation for vaginal candidiasis. These are important initial results that need to be developed. Further studies are required to determine whether this novel approach to treatment should be recommended.

\section{Acknowledgements}

The authors would like to thank to Scientific and Technological Research Council of Turkey (TUBITAK) (115S476) for their support. The authors also would like to thank to Pharmaceutical Sciences Research Centre (FABAL) for their support.

\section{References}

[1] Johal, H.S., Garg, T., Rath, G. and Goyal, A.K. (2016). Advanced Topical Drug Delivery System for the Management of Vaginal Candidiasis. Drug Delivery, 23, 550-563. https://doi.org/10.3109/10717544.2014.928760

[2] Nyirjesy, P. (2008) Vulvovaginal Candidiasis and Bacterial Vaginosis. Infectious Disease Clinics of North America, 22, 637-652.

https://doi.org/10.1016/j.idc.2008.05.002

[3] Rosalinde, H. and Louvois, J.D. (1979) Candida Vaginitis. Postgraduate Medical Journal, 55, 645-647. https://doi.org/10.1136/pgmj.55.647.645

[4] Jack, D.S., Wiesenfelt, H.C., Martens, M., Danna, P., Hooton, T.M., Rompalo, A., Sperling, M., Livengood III, C., Horowitz, B., Thron, J.V., Edwards, L., Panzer, H. and Chu, T.C. (2004) Maintenance Fluconazole Therapy for Recurrent Vulvovaginal Candidiasis. The New England Journal of Medicine, 351, 876-883. https://doi.org/10.1056/NEJMoa033114

[5] Kalavathy, C.M., Parmar, P., Kaliamurthy, J., Philip, V.R., Ramalingam, M.D.K., Jesudasan, C.A.N. and Thomas, P.A. (2005) Comparison of Topical Itraconazole 1\% with Topical Natamycin 5\% for the Treatment of Filamentous Fungal Keratitis. Clinical Sciences, 24, 449-452. https://doi.org/10.1097/01.ico.0000151539.92865.3e

[6] Fucinos, C., Guerra, N.P., Teijon, J.M., Pastrana, L.M., and Katime, I. (2012) Use of poly(N-isopropylacrylamide) Nanohydrogels for the Controlled Release of Pimaricin in Active Packaging. Journal of Food Science, 77, 21-28. https://doi.org/10.1111/j.1750-3841.2012.02781.x

[7] Özguney, I., Shuwisitkul, D. and Bodmeier, R. (2009) Development and Characterization of Extended Release Kollidon SR Mini-Matrices Prepared by Hot-Melt Ex- 
trusion. European Journal of Pharmaceutics and Biopharmaceutics, 73, 140-145. https://doi.org/10.1016/j.ejpb.2009.04.006

[8] Zhu, Y., Navnit, H.S., Malick, A.W., Infeld, M.H. and McGinity, J.W. (2006) Controlled Release of a Poorly Water-Soluble Drug from Hot-Melt Extrudates Containing Acrylic Polymers. Drug Development and Industrial Pharmacy, 32, 569-583. https://doi.org/10.1080/03639040500528996

[9] Alexander, N.J., Baker, E., Kaptein, M., Karck, U., Miller, L. and Zampaglione, E. (2004) Why Consider Vaginal Drug Administration? Fertility and Sterility, 82, 1-12. https://doi.org/10.1016/j.fertnstert.2004.01.025

[10] Vermani, K. and Garg, S. (2000) The Scope and Potential of Vaginal Drug Delivery. PSTT, 3, 359-364. https://doi.org/10.1016/S1461-5347(00)00296-0

[11] Duchêne, D. and Ponchel, G. (1992) Principle and Investigation of the Bioadhesion Mechanism of Solid Dosage Forms. Biomaterials, 13, 709-714. https://doi.org/10.1016/0142-9612(92)90132-8

[12] Cevher, E., Şensoy, D., Zloh, M. and Mülazimoğlu, L. (2008) Preparation and Characterisation of Natamycin: Gamma-Cyclodextrin Inclusion Complex and Its Evaluation in Vaginal Mucoadhesive Formulations. Journal of Pharmaceutical Sciences, 97, 4319-4335. https://doi.org/10.1002/jps.21312

[13] Repka, M.A. and McGinity, W.J. (2001) Bioadhesive Properties of Hydroxypropylcellulose Topical Films Produced by Hot-Melt Extrusion. Journal of Controlled Release, 70, 341-351. https://doi.org/10.1016/S0168-3659(00)00365-5

[14] Repka, M.A. and McGinity, W.J. (2001) Influence of Chlorpheniramin Maleate on Topical Hydroxypropylcellulose Films Produced by Hot-Melt Extrussion. Pharmaceutical Development and Technology, 6, 297-304.

https://doi.org/10.1081/PDT-100002610

[15] Karavana, S.Y., Rençber, S., Şenyiğit, Z.A. and Baloğlu, E. (2012) A New In-Situ Gel Formulation of Itraconazole for Vaginal Administration. Pharmacology and Pharmacy, 3, 417-426. https://doi.org/10.4236/pp.2012.34056

[16] http://www.ashland.com/file_source/Ashland/Product/Documents/Pharmaceutical/ PC_11229_Klucel_HPC.pdf

[17] Repka, M.A., Gerding, T.G., Repka, S.L. and McGinity, J.W. (1999) Influence of Plasticizers and Drugs on the Physical-Mechanical Properties of Hydroxypropylcellulose Films Prepared by Hot Melt Extrusion. Drug Development and Industrial Pharmacy, 25, 625-633. https://doi.org/10.1081/DDC-100102218 